\title{
Long-term evolution of the S788 fungal nuclear small subunit rRNA group I introns
}

\author{
PEIK HAUGEN, HENRY JOSEPH RUNGE, and DEBASHISH BHATTACHARYA \\ Department of Biological Sciences and Center for Comparative Genomics, University of lowa, lowa City, lowa 52242, USA
}

\begin{abstract}
More than 1000 group I introns have been identified in fungal rDNA. Little is known, however, of the splicing and secondary structure evolution of these ribozymes. Here, we use a combination of comparative and biochemical methods to address the evolution and splicing of a vertically inherited group I intron found at position 788 in the fungal small subunit (S) rRNA. The ancestral state of the S788 intron contains a highly conserved core and an extended P5 domain typical of IC1 introns. In contrast, the more derived introns have lost most of P5, and have an accelerated divergence rate within the core region with three functionally important substitutions that unambiguously separate them from the ancestral pool. Of 14 S788 group I introns that were tested for splicing, five, all of the ancestral type, were able to self-splice and produced intron RNA circles in vitro. The more derived S788 introns did not self-splice, and potentially rely on fungal-specific factors to facilitate splicing. In summary, we demonstrate one possible fate of vertically inherited group I introns, the loss of secondary structure elements, lessened selective constraints in the intron core, and ultimately, dependence on host-mediated splicing.
\end{abstract}

Keywords: group I introns; ribosomal RNA; Cyt 18; intron evolution; intron splicing

\section{INTRODUCTION}

Group I introns are large ribozymes that catalyze their own excision from preRNAs (for review, see Cech 1990). The two-step self-splicing reaction is often autocatalytic in vitro, but is thought to be assisted by protein factors in vivo (e.g., Lambowitz and Perlman 1990; Lambowitz et al. 1999; Solem et al. 2002). The secondary and tertiary structure of group I introns is critical for splicing and is therefore under strong selection. This suggests that RNA structure should provide a useful tool for gaining insights into intron evolution, that is, alterations in intron structure are expected to have implications for intron splicing and thereby host fitness.

The interplay between intron RNA structure (i.e., both secondary and tertiary) and splicing has been most thoroughly studied in the model Tetrahymena thermophila large subunit (L) rRNA group I intron. This ribozyme forms a close-packed RNA structure (for review, see Cech and Golden 1999). As a member of the IC1 subgroup (Michel and Westhof 1990), the Tetrahymena intron contains a large P5abc domain that folds back onto the P4 and P6 paired

Reprint request to: Debashish Bhattacharya, Department of Biological Sciences and Center for Comparative Genomics, University of Iowa, 210 Biology Building, Iowa City, IA 52242-1324, USA; e-mail: dbhattac@blue. weeg.uiowa.edu; fax: (319) 335-1069.

Article and publication are at http://www.rnajournal.org/cgi/doi/ 10.1261/rna.5202704. elements (Flor et al. 1989; Costa and Michel 1995; Cate et al. 1996). The folded P4-P6 domain (also called the folding domain) functions as a scaffold to stabilize the final ribozyme structure that includes the P3-P9 stack of paired elements and the P1-P2 substrate domain. In contrast, the two closely related group IC3 introns from Azoarcus sp. HB72 and Synechococcus PCC6301 tRNA genes have a different strategy for ribozyme activation. Instead of having extra peripheral elements like P5abc to stabilize the core, these introns appear to have undergone extensive alterations in the ribozyme core itself. For example, two basetriple interactions (P4XJ6/7) in these introns greatly increase ribozyme activity (Ikawa et al. 2000a). The base triplets are able to weakly activate splicing in the ciliate ribozyme when introduced into a Tetrahymena intron variant lacking P5abc (Ikawa et al. 2002). These studies demonstrate that group I introns may have different strategies for achieving autocatalysis that reflect significant alterations in the RNA structure.

Within the fungi, there is a vast array of group I introns in nuclear rDNA (>1000 introns; Cannone et al. 2002), of which little is known about splicing and secondary structure evolution (for exceptions, see DePriest and Been 1992; Suh et al. 1999). These introns display a diversity of evolutionary histories (e.g., mobility [Hibbett 1996; Bhattacharya et al. 2002; Haugen and Bhattacharya 2004]; long-term vertical inheritance [e.g., Haugen et al. 2004]) and RNA secondary 
structures (see http://www.rna.icmb.utexas.edu/). In this study, we set out to understand the evolution and splicing ability of a vertically inherited group I intron in the fungal small subunit (S) rRNA at position 788 (by convention, the numbering reflects the Escherichia coli genic position). A combination of comparative and biochemical methods was used to explore RNA structure and splicing on a phylogeny of the S788 intron.

\section{RESULTS AND DISCUSSION}

\section{Secondary structure and self-splicing of fungal S788 introns}

We studied the family of fungal nuclear S788 group I introns. Of the 25 currently known S788 introns (when counting introns from closely related species as a single entry; see Table 1), none have thus far been shown to encode a homing endonuclease gene, therefore making it more likely that these introns are vertically inherited (see also phylogenetic analyses below). Analysis of the predicted RNA secondary structures of these introns revealed a very similar overall folding of the ribozyme, with the exception of the peripheral P5 region (Fig. 1). The P5 domain varies from having a P5abcd extension typical of the IC1 intron subgroup (i.e., Geosmithia virida, Penicillium oblatum, Delitschia didyma [hereafter referred to as the +P5ext introns]) to being extremely short (i.e., Lecanora dispersa, Buellia georgei [hereafter referred to as the -P5ext introns]). Figure 2 shows an alignment of the S788 intron sequences. Four potential long-range RNA-RNA interactions (see inset in Fig. 2) appear to be exclusively found in the +P5ext

TABLE 1. Summary of fungal S788 group I intron characteristics

\begin{tabular}{|c|c|c|c|c|c|c|}
\hline Organism $^{a}$ & $\begin{array}{l}\text { Plasmid } \\
\text { name }^{\text {b }}\end{array}$ & Res. enzyme & $\begin{array}{l}\text { Intron } \\
\text { size (nt) }\end{array}$ & $\begin{array}{c}\text { Splicing } \\
\text { in vitro/in vivo }\end{array}$ & $\begin{array}{l}\text { Intron } \\
\text { circles }^{d}\end{array}$ & Accession no. ${ }^{e}$ \\
\hline Acarospora complanata & pAco.S788 & Spel & 248 & $-/ N A$ & NA & AF356653 \\
\hline Acarospora cf. dissipata & - & - & 242 & NA/NA & NA & AF356655 \\
\hline Amandinea punctata & - & - & 214 & NA/NA & NA & AY547738 \\
\hline Ascolacicola austriaca & pAau.S788 & Spel & 379 & $* * / \mathrm{NA}$ & $\mathrm{FL}(2)$ & AY547739 \\
\hline Baeomyces placophyllus & pBpl.S788 & Spel & 333 & $-/ N A$ & NA & AF356657 \\
\hline Barrmaelia oxyacanthae & pBox.S788 & Mlul/Hincl & 299 & ***/NA & $\mathrm{FL}(5),-2(1)$ & AY547740 \\
\hline Buellia georgei & pBge.S788 & Spel & 213 & $-/ N A$ & & AJ421681 \\
\hline Delitschia didyma & pDdi.S788 & Sall & 341 & */NA & $-45(6)$ & AY547741 \\
\hline Dermatocarpon americanum & - & - & 283 & $\mathrm{NA} /+$ & NA & AF279383 \\
\hline Dimeralla lutea & - & - & 204 & NA/NA & NA & AF279386 \\
\hline Diploicia canescens & - & - & 214 & NA/NA & NA & AJ421684 \\
\hline Geosmithia virida & pGvi.S788 & Spel/Hincll & 340 & $* * * /+$ & $-41(4),-42(1)$ & AB033527 \\
\hline Gymnoderma coccocarpum & - & - & 252 & NA/NA & NA & AF523362 \\
\hline Heppia adg/utinata & - & - & 196 & NA/NA & NA & AY547742 \\
\hline Lecanora dispersa & Ldi.S788 & Spel & 213 & $-/ N A$ & NA & AY547743 \\
\hline Muscodor sp. A10-1 & - & - & 339 & & & AY049023 \\
\hline Myriosclerotinia caricis-ampullaceae & - & - & 430 & $\mathrm{NA} /+$ & NA & AJ226069 \\
\hline Myriosclerotinia curreyana & - & - & 292 & NA/NA & NA & AJ226070 \\
\hline Myriosclerotinia dennisii & - & - & 294 & NA/NA & NA & AJ226072 \\
\hline Myriosclerotinia scirpicola & pMsc.S788 & Spel & 293 & $-/+$ & NA & AJ226073 \\
\hline Penicillium oblatum & pPob.S788 & Spel/Hincll & 352 & $* * * /+$ & $-49(2)$ & AB033529 \\
\hline Petractis clausa & - & - & 260 & NA/NA & NA & AF356661 \\
\hline Physcia aipolia & - & - & 227 & $\mathrm{NA} /+$ & NA & AF421687 \\
\hline Physcia stellaris & pPst.S788 & Sall & 215 & $-/+$ & NA & AY547744 \\
\hline Physconia perisidiosa & - & - & 208 & NA/NA & NA & AJ421689 \\
\hline Pyrenula cruenta & pPcr.S788 & Spel & 302 & $-/ N A$ & NA & AF279406 \\
\hline Rhynchostoma minutum & pRmi.S788 & Spel & 356 & $-/ N A$ & NA & AF242268 \\
\hline Rinodina cacuminum & pRca.S788 & Spel & 208 & $-/ N A$ & NA & AJ421690 \\
\hline Sporobolomyces dimmenae (B) & - & - & 221 & NA/NA & NA & D66881 \\
\hline
\end{tabular}

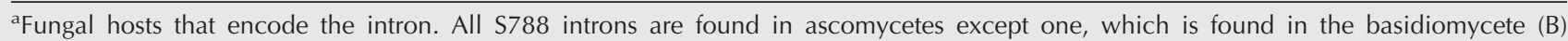
Sporobolomyces dimmenae.

bPlasmid constructs are named according to current rDNA intron nomenclature (Johansen and Haugen 2001).

'Self-splicing data. Efficient $\left({ }^{* * *}\right)$, moderate $\left(^{* *}\right)$ or weak $(*)$ in vitro self-splicing is indicated to the left, and detected in vivo self-splicing is indicated to the right (+). (NA) Not analyzed.

${ }^{d}$ Intron RNA circle junctions. Circles were found by using RT-PCR with RNA from in vitro self-splicing assays as templates. Full-length (FL) or $5^{\prime}$ truncated intron circles lacking various numbers of nucleotides $(-\mathrm{nn})$ are shown. Numbers in parentheses indicated the total number of clones sequenced that represent this type of circle. (NA) Not analyzed.

${ }^{\mathrm{e} G e n B a n k}$ accession numbers. Intron sequences that were found to contain multiple sequence differences from the GenBank equivalent data (Ascolacicola austriaca, AF242263; Barrmaelia oxyacanthae, AF064048; Delitschia didyma, AF242264; Lecanora dispersa, L37734; and Physcia stellaris, AJ421688) have been given new accession numbers. 


\section{P4-P6}

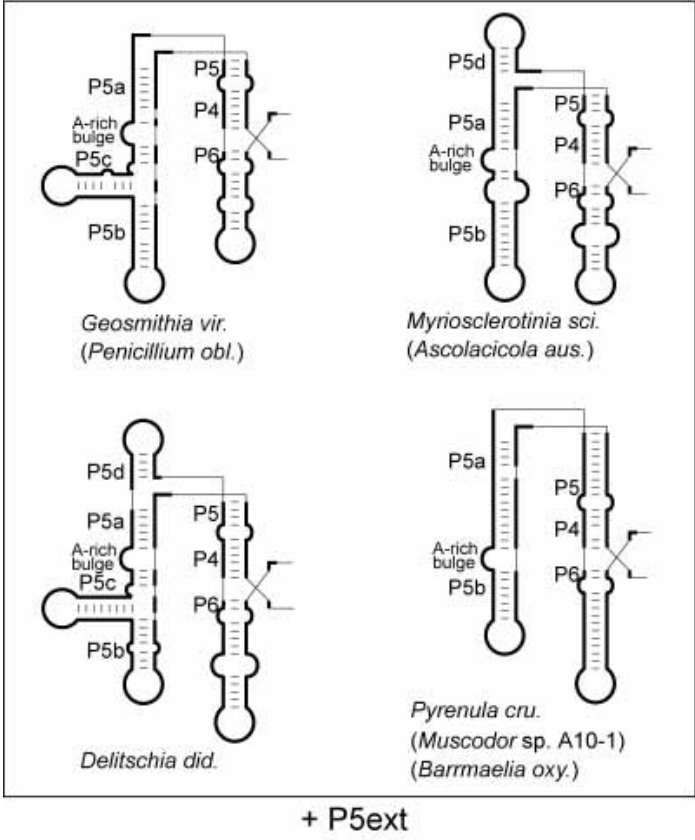

+ P5ext

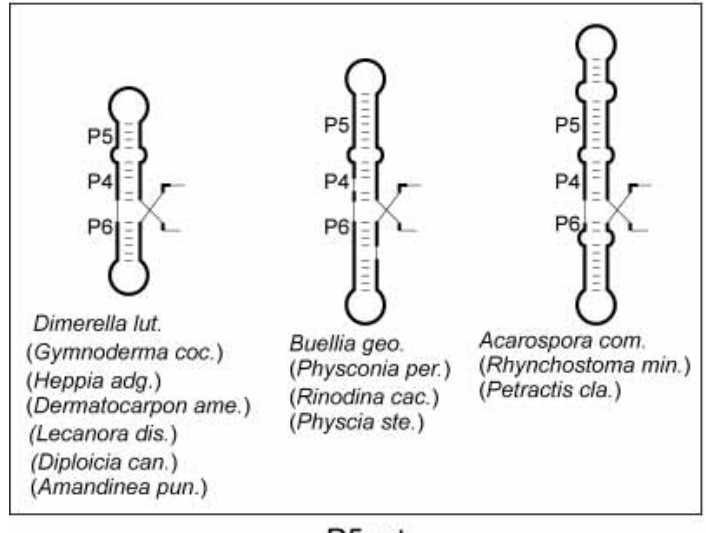

- P5ext

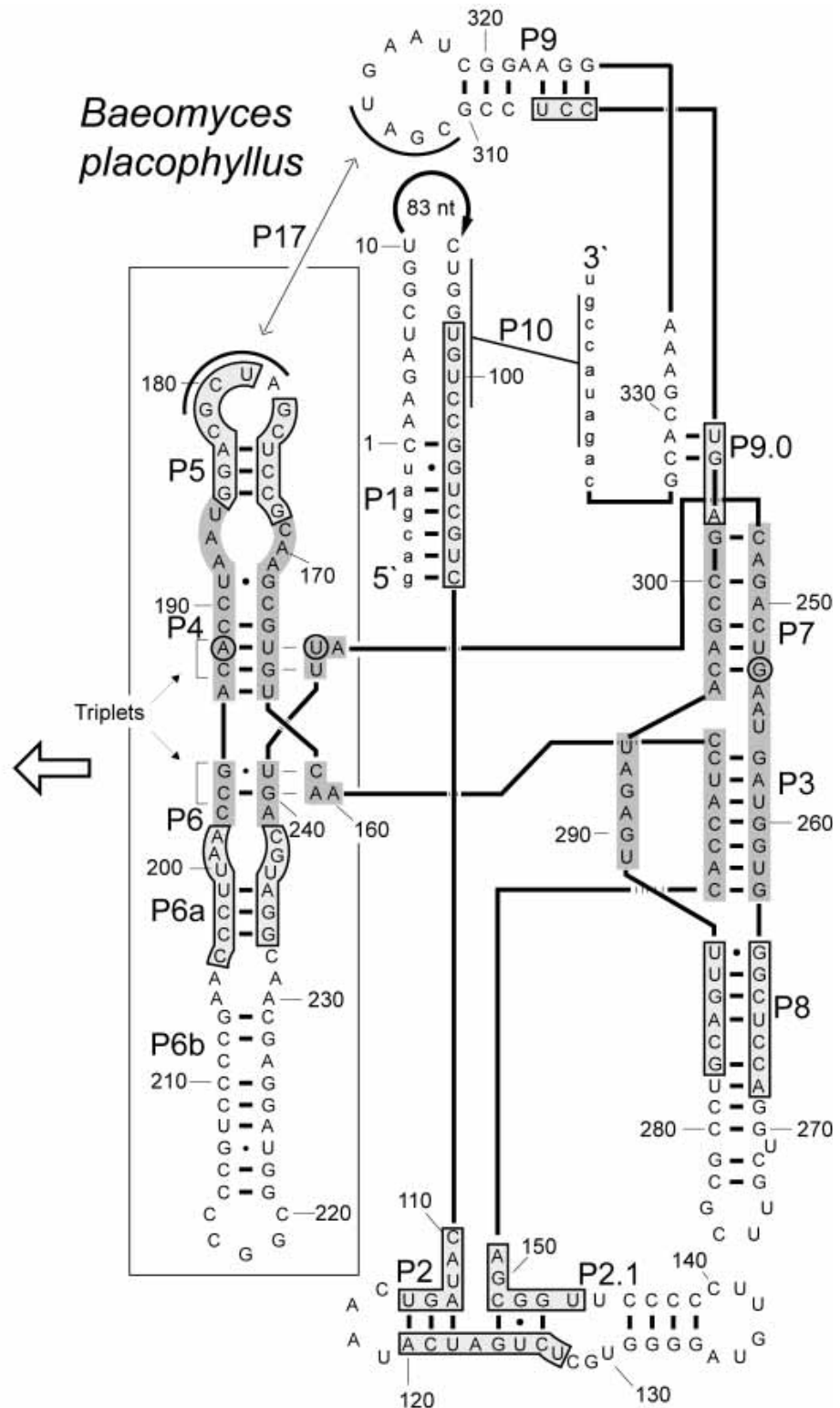

120

FIGURE 1. Putative secondary structures of fungal S788 group I introns. Variation in the P4-P6 domain among fungal S788 introns are shown at left, and the secondary structure of the Baeomyces placophyllus S788 group I intron is shown at right. Introns with short (-P5ext) or long (+P5ext) peripheral P5 regions are shown. Paired elements (P1-P10, P17) and numbering of every tenth nucleotide position in the intron are marked on the structure. The thin line with arrows at both ends indicates the hypothetical P17 loop-loop interaction. Intron positions defined as the ribozyme catalytic central core $(68 \mathrm{nt})$ are indicated (dark gray-shaded positions). Boxed positions were used together with the core positions (249 nt) to infer the phylogeny of the S788 introns. Positions in P5abc domain were also used in the 249-nt data set, but are not present in the Baeomyces placophyllus intron. The three circled positions unambiguously distinguish the short from the long introns in a character analysis using the ML tree inferred from the 68-nt core data set (see Fig. 6A,B).

introns, including interactions between (1) GAAA tetraloops in L5b and L9, and 11-nt receptors in P6 and J5/5a, respectively (Costa and Michel 1995; Ikawa et al. 2000b), (2) the A-rich bulge and the P4 paired element (Cate et al. 1996; Ikawa et al. 2002), and (3) the highly conserved A in $\mathrm{J} 4 / 5$ that is involved in defining the universally conserved G.u wobble pair in P1 (Michel and Westhof 1990; OrtolevaDonnelly et al. 1998; Strobel et al. 1998). The GAAA/11-nt receptor interaction between L9 and the P5 region might, however, be replaced by other types of RNA-RNA contacts (e.g., Jaeger et al. 1994; Lehnert et al. 1996). In at least three of the -P5ext introns (Baeomyces [see Fig. 1], Dimerella, and Acarospora) there are potential loop-loop base pairings between L9 and L5 (P17; see Lehnert et al. 1996). The P2 and P8 elements contain a high degree of sequence variation, but no clear structural or functional differences could be assigned to these regions. A strictly conserved UAG motif is found in the junction between the P2 and P2.1 elements 


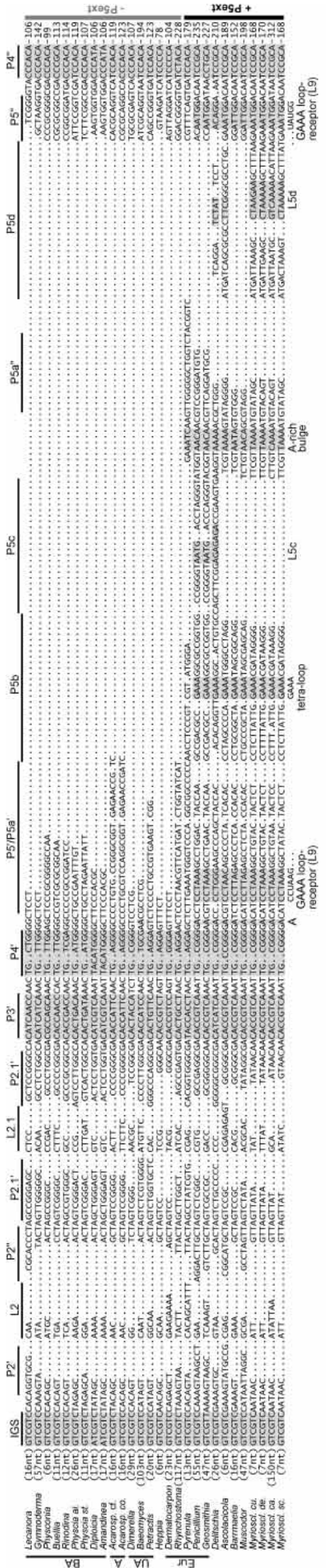

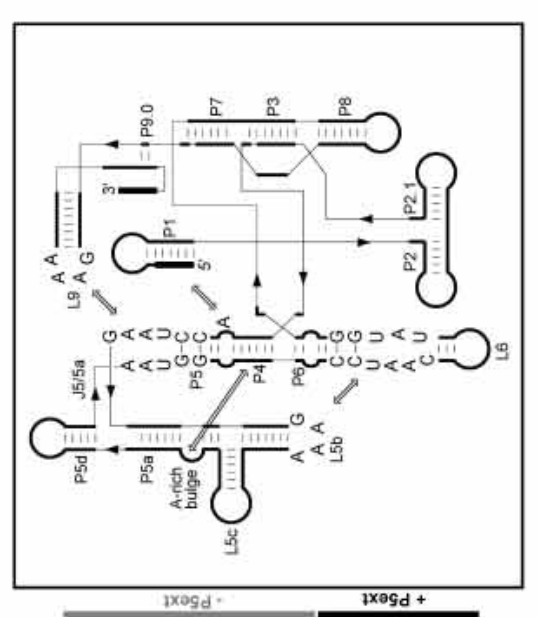

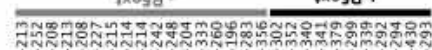

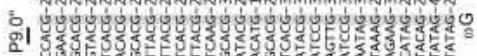

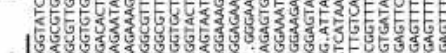

\$.

-

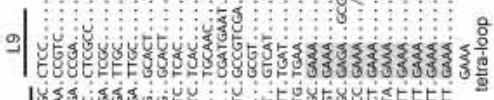
a

¿1

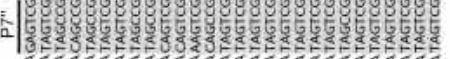

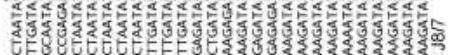

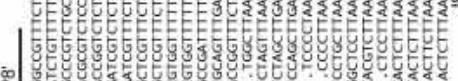

\% 040

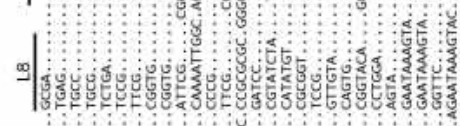

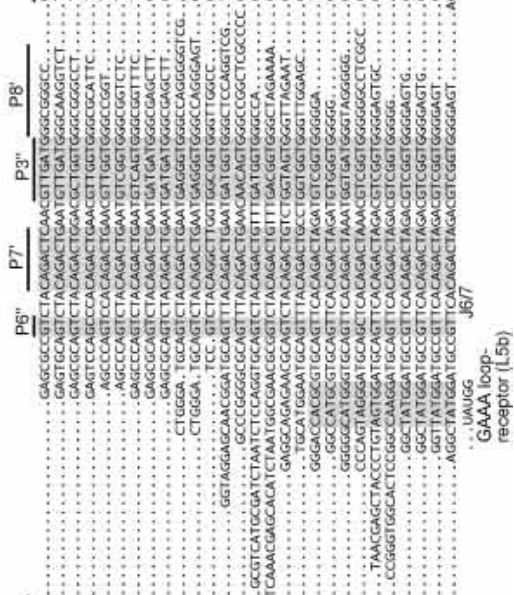

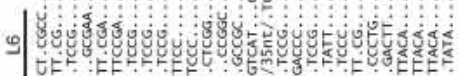

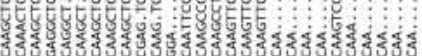

ใ०

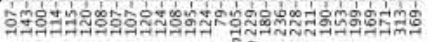

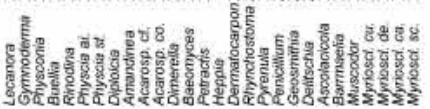

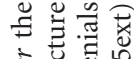

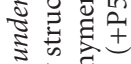

च्ञ

วั ธี

\&

ช.

苞寻声

蒠总

\& ज्ञ के

志氙责

콬

की

त्ते के

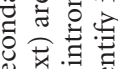

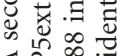

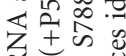

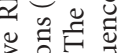

昰额

है

눨 능

인

邫灾

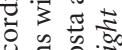

氜

咭芯

붕요

․․ำ

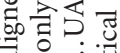

氜

ช 政

记导芯

要过苛

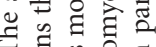

.0ํ요.

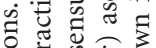

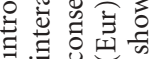

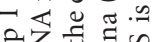

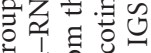

क人⿻心

$\infty$ Z吉志

क s

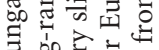

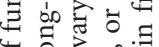

일

可完范

迎氙记

ज苛焉 品

U్ర

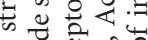

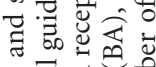

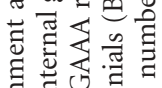

.50

ช

氖记

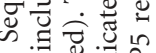

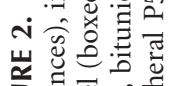

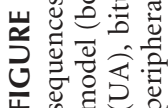


(positions 122-124 in Baeomyces, Fig. 1). In the Tetrahymena ribozyme, the central A is thought to play a role in tethering P1 into the active site (Ortoleva-Donnelly et al. 1998).

To test the S788 introns for self-splicing ability, 14 introns that included members with differing P5 structures (see Figs. 1, 2) were amplified with PCR (including flanking exons) and cloned for in vitro expression. Pre-RNA was in vitro transcribed from linearized plasmids and subjected to conditions that favor self-splicing (see Materials and Methods for details). RNA products from time-course experi- ments were run on 5\% PAGE gels and ethidium-bromide (EtBr) stained for visualization. To detect weak splicing not visible by EtBr staining, we also used the splicing reactions as templates for reverse transcription (RT) and PCR (RTPCR) using primers that recognize the flanking exons. For four of the introns, the RNA products corresponding to the sizes of the free intron and the ligated exons could be readily visualized on EtBr-stained gels (Fig. 3A-D; summarized in Fig. 5, below, and Table 1). In addition, our RT-PCR approach amplified a product consistent with the size of the ligated exons for Delitschia. This product was also found for
A

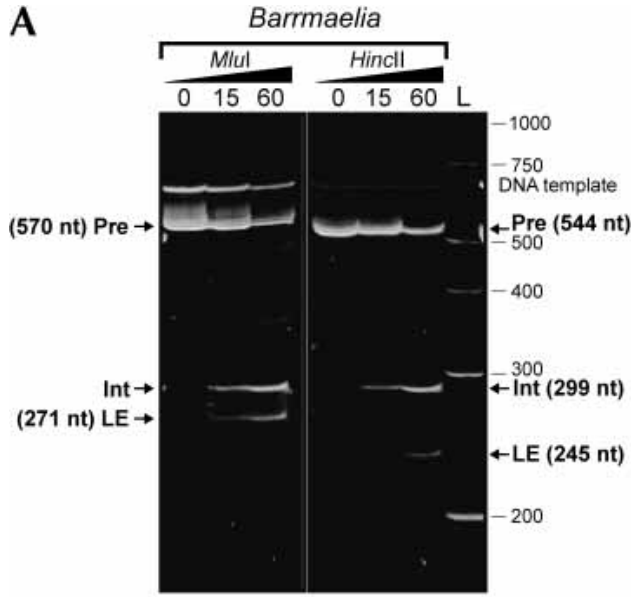

D

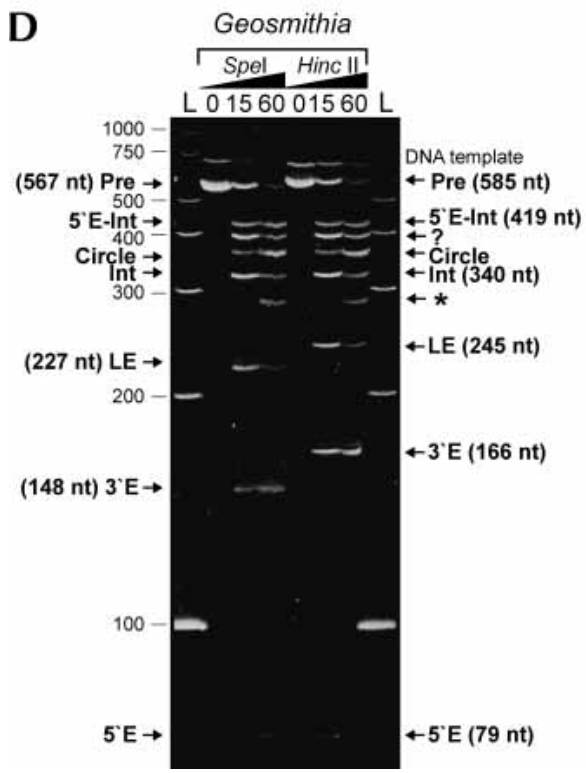

B

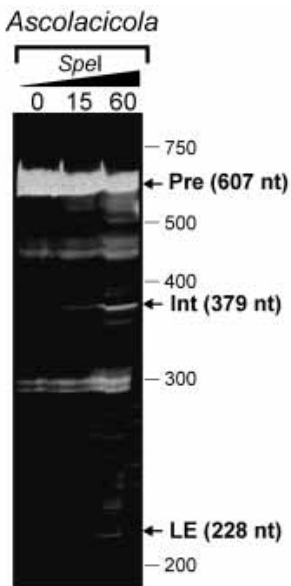

$\mathbf{E}$

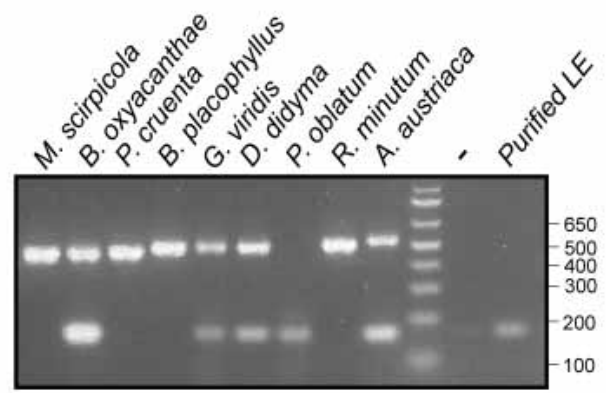

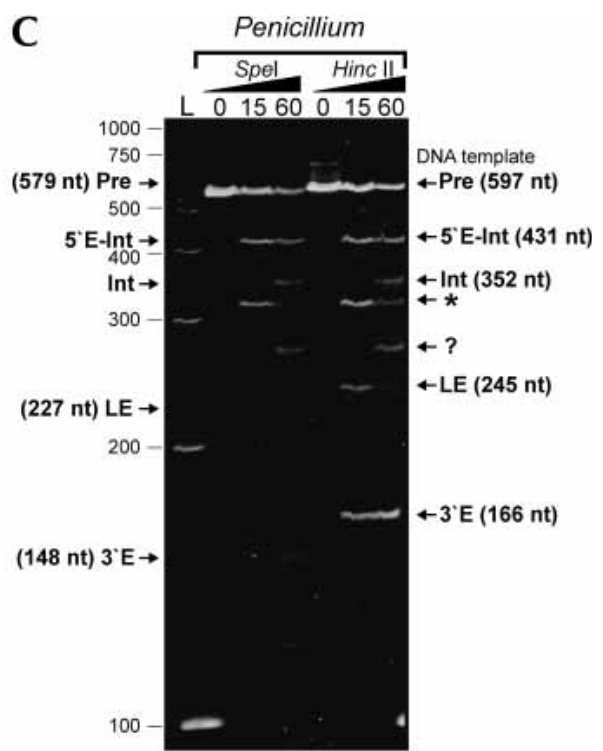

FIGURE 3. In vitro splicing analysis of fungal S788 introns. (A-D) Intron RNAs were subjected to conditions favoring self-splicing in time-course experiments and run on polyacrylamide gels. Precursor RNAs (Pre), ligated exons RNA (LE), excised intron RNAs (Int), 5' and 3' exon RNAs (5'E and 3'E), and intron circle RNAs (circle) are indicated. RNA circles were identified by running the RNA samples under different buffer conditions and looking for mobility shifts relative to the ladder. RNAs that most likely correspond to reopened circles are indicated by asterisk ${ }^{*}$ ) and RNAs of unknown nature are marked with a question mark (?). (E) The RNA samples that were in the splicing reaction for 60 min were also used as templates in RT-PCR reactions using flanking exon primers to detect low levels of self-splicing. PCR-amplified DNA corresponding to ligated exons (LE) was run alongside the samples as control. The lane marked with $(-)$ is the negative control. 
the four self-splicing introns that were detected directly on the RNA gels (Fig. 3E). No bands were detected for the other introns (see Fig. 3E). Sequencing of the RT-PCR products confirmed correct exon ligation (data not shown). Interestingly, the five introns that were found to self-splice in vitro (see Fig. 5, below) are all S788 introns that encode P5 extensions (+P5ext; Fig. 1).

In addition to self-splicing, group I introns can also catalyze side reactions including 3' splice site (SS) hydrolysis and intron RNA circle formation (Inoue et al. 1986; Golden and Cech 1996; Haugen et al. 2002; Nielsen et al. 2003). In an RT-PCR approach, we amplified products corresponding to the circle junctions for all of the five S788 introns demonstrated to self-splice in vitro (data not shown). Amplified products were sequenced and the circle junctions were determined for each intron (summarized in Table 1). Circles were identified for all introns shown to self-splice.
The P1 or a P1-like structure was found by folding the internal guide sequence of the introns to the sequence immediately upstream of the circle junctions. Therefore, of the 14 S788 group I introns tested for in vitro activity, five were able to self-splice and produced full-length or $5^{\prime}$-truncated intron RNA circles (summarized in Table 1).

\section{S788 introns in ascomycete fungi have a single origin in their common ancestor}

To address the issue of S788 intron origin in the ascomycete fungi, we compiled a data set containing the ribozyme core region (115 nt) of the $\mathrm{S} 788$ introns and other introns that are of the highest frequency in ascomycete SSU rDNA. A summary of the neighbor-joining (NJ) intron phylogeny inferred from this data set is shown in Figure 4A (the original tree is available upon request from DB). This tree sup-

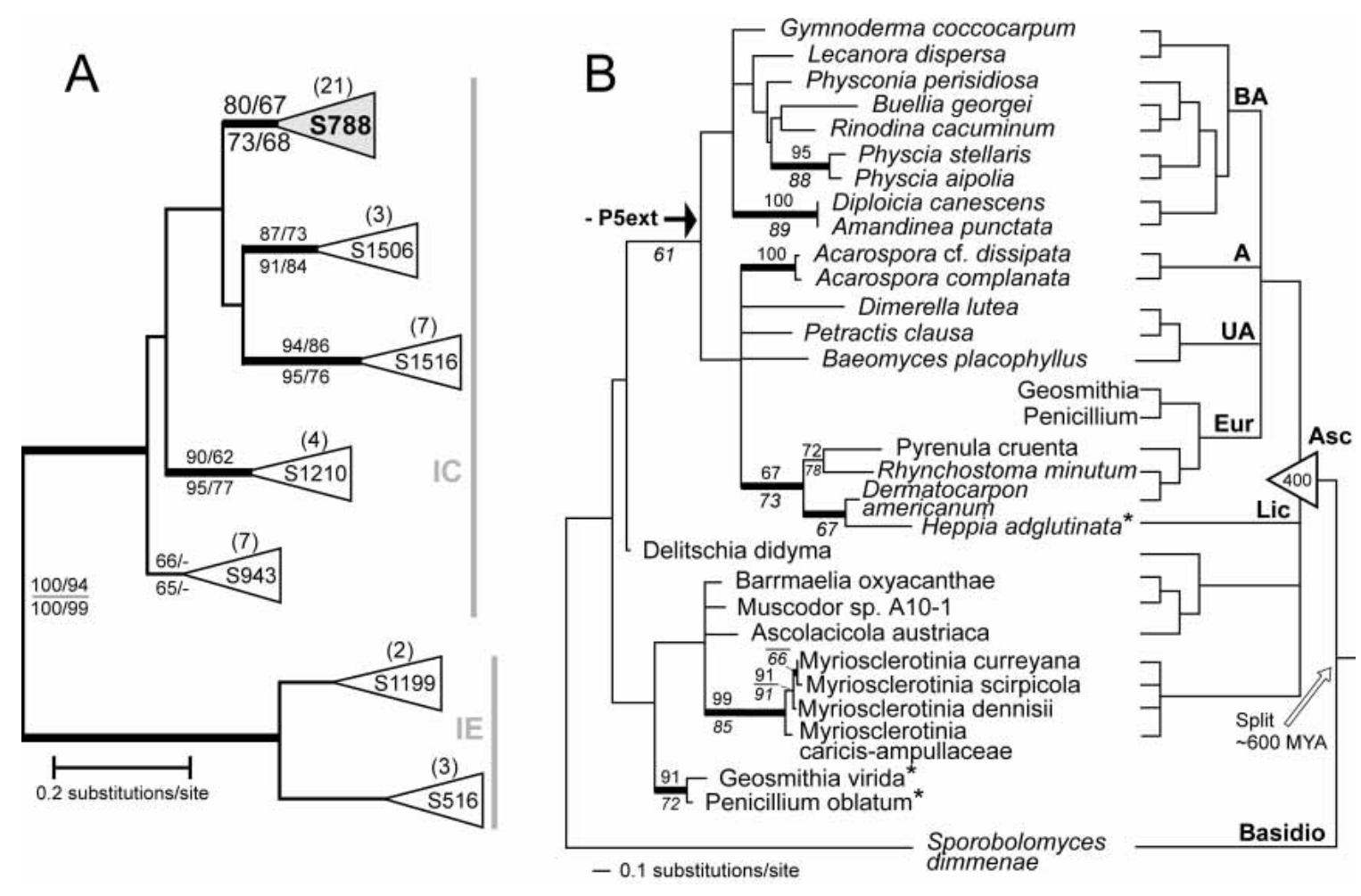

FIGURE 4. Phylogeny of ascomycete nuclear group I introns in SSU rDNA. (A) Summary of a NJ-JC tree that incorporates a broad sampling of fungal introns. Twenty-one S788 introns and 26 introns from six other SSU rDNA sites (the number of introns representing each site is shown in parenthesis) show phylogenetic clustering based on the site of insertion. Bootstrap values above the internal nodes were inferred from a NJ-JC (left), or NJ-Kimura 2 (right) analysis, whereas minimum evolution-JC (left) and maximum parsimony bootstrap values are shown below the nodes. Only bootstrap values $\geq 60$ are shown. The thick branches denote $>95 \%$ posterior probability for groups to the right resulting from a Bayesian inference (GTR $+\Gamma$ model). The separation of the distantly related subgroup IE and IC introns is highly supported. (B) The ML tree $(\mathrm{GTR}+\Gamma$ model) shown at left is based on an alignment of $249 \mathrm{nt}$ from the S788 introns. Bootstrap values above the internal nodes were inferred from a minimum evolution-GTR $+\Gamma$ analysis, whereas ML-quartet-puzzling values (Tamura-Nei $+\Gamma$ model) are shown below the nodes. Only bootstrap or puzzle values $\geq 60$ are shown. The thick branches denote $>95 \%$ posterior probability for groups to the right resulting from a Bayesian inference (GTR $+\Gamma$ model). Juxtaposed to the intron tree is a cladogram showing the putative phylogenetic relationships among fungi (Lutzoni et al. 2001; F. Lutzoni and V. Reeb, pers. comm.). The relative positions of basidiomycetes (Basidio), ascomycetes (Asc), unitunicate ascohymenials (UA), bitunicate ascohymenials (BA), Acarosporaceae (A), Eurotiomycotina (Eur), and Lichinales (Lic) are shown. The oldest known ascomycete fossil (400 million years old; Taylor et al. 1999) and the estimated time of split of the ascomycete and basidiomycete fungi (600-620 million years ago; Redecker et al. 2000) are shown. Introns with a short peripheral P5 region are referred to as "-P5ext" introns and are shown in italic text (see Figs. 1, 2). 
ports the phylogenetic clustering of ascomycete introns on the basis of their site of insertion in SSU rDNA. The S788 clade has significant Bayesian support and moderate bootstrap support, thus suggesting the origin of S788 introns in ascomycetes through a single insertion in their common ancestor. This result is in agreement with previous studies of rDNA group I intron evolution that incorporate a broader sampling of introns from different insertion sites (e.g., Bhattacharya 1998; Tanabe et al. 2002; Bhattacharya et al. 2003; Haugen et al. 2003; Haugen and Bhattacharya 2004). Our results do not, however, formally exclude the possibility that introns from sources other than those that were included in the phylogenetic analyses could be related to the ascomycete S788 introns.

\section{Phylogeny of the S788 introns and structural implications}

Given that there is reasonable evidence for a common origin of ascomycete S788 introns, then what is likely to have been the ancestral state of this intron? To gain insights into this question, we specifically aligned all of the S788 introns and reconstructed their phylogenetic history. A maximum likelihood (ML) tree of the S788 intron sequences using the 249-nt data set, with Sporobolomyces dimmenae (Basidiomycota) as the outgroup, is shown in Figure 4B. The basidiomycete fungi are sister to the ascomycetes (e.g., Lutzoni et al. 2001) and therefore, as would be predicted, the S788 intron in Sporobolomyces is phylogenetically distantly related to the ascomycete introns. To test whether the S788 intron has been laterally transferred among ascomycetes, we generated a cladogram that represents present knowledge of fungal relationships (e.g., Bhattacharya et al. 2000; Lutzoni et al. 2001; F. Lutzoni and V. Reeb, pers. comm. [see also the Deep Hypha site, http://lsb380.plbio.lsu.edu/network\%20folder/ network\%20proposal]). Also indicated on the cladogram are the dates of the oldest known ascomycete fossils (400 million years old; Taylor et al. 1999) and the estimated time of split between the ascomycete and basidiomycete fungi (600-620 million years ago; Redecker et al. 2000). Comparison of the intron (Fig. 4B, left) and host (Fig. 4B, right) trees shows that in spite of low resolution over many nodes in the intron tree (typical for these short sequences, e.g., Haugen et al. 2004), that there is generally good topological congruence over many regions that are well supported with both bootstrap and Bayesian analyses. This suggests that the S788 intron has been vertically inherited among most fungi in the tree. Two noteworthy topological conflicts with significant support are the positions of Heppia adglutinata and of the two closely related species, Geosmithia virida and Penicillium oblatum (marked with asterisks in Fig. 4B). These introns are potential candidates for lateral transfer within the ascomycetes. In the Heppia case, the intron is most closely related to other S788 introns in the Eurotiomycotina (Eur in Fig. 4B), whereas the host cell is a member of the Lichinales (Lic). This suggests a group I intron lateral transfer into Heppia from a Euromycotina source. In contrast, Geosmithia and Penicillium are members of the Euromycotina, but contain S788 introns from a more ancestral ascomycete donor. Interestingly, the +P5ext introns, whether they are vertically inherited or originate through a potential lateral transfer (except Pyrenula cruenta), are positioned at the base of the intron tree, with a relatively long branch separating these sequences (after the divergence of Delitschia) from the generally shorter -P5ext introns. Although this branch does not have significant bootstrap or Bayesian support, it suggests that the presence of P5abcd is the ancestral condition in the S788 introns and that the -P5ext introns represent a derived state, potentially as a result of a single deletion event (e.g., by unequal crossing over) or possibly stepwise deletions in the P5 region. In either case, we expect that clear hallmarks of the deletion(s) would be erased by random genetic drift or by lineagespecific adaptations that have occurred since the split of the + P5ext- and -P5ext-containing fungi. This event took place sometime after 400 million years ago, following the separation of ascomycete and basidiomycete fungi (see host cladogram in Fig. 4B). Given this hypothesis, then Pyrenula appears to have retained (or possibly independently reverted back to) the ancestral intron state with a larger P5 domain.

In an attempt to understand the differences in intron structure and phylogeny between the -P5ext and +P5ext introns, we created a second intron alignment that contained sequences only from the central core of the ribozyme (dark-gray shaded area in Fig. 1). The core data set excluded potentially confounding phylogenetic signal found in the less well-conserved, peripheral intron regions. In Baeomyces, the 68 core positions correspond to nucleotides 152171, 186-197, 239-263, and 289-301. Phylogenetic analyses were done as described above with the 68-nt data set (Fig. $5)$. Even with only 68 characters, we were able to recover much of the same branching pattern found in the former intron tree. The support for origin through lateral transfer of the Heppia, Geosmithia, and Penicillium introns is increased in the core tree. The resolution among groups and the branch lengths of the +P5ext introns were, however, greatly reduced. This indicates that the ribozyme core is relatively more highly conserved in the self-splicing than in the remaining introns, most likely reflecting stronger selection for retaining ribozyme activity. Clearly, exclusion of the peripheral regions from the ML analysis lowered phylogenetic signal in the $+\mathrm{P} 5$ ext intron clade. Consistent with these ideas, the average pairwise evolutionary distance between introns in the 249-nt and the core (68-nt) data sets, using the Tamura-Nei $+\Gamma$ evolutionary model, differed by a factor of $1.8(-\mathrm{P} 5$ ext $=0.49,+\mathrm{P} 5$ ext $=0.88)$. In contrast to the 249-nt data set, the separation of the +P5ext and -P5ext intron clades was significantly supported by the Bayesian and TreePuzzle analyses of the core region. These findings 

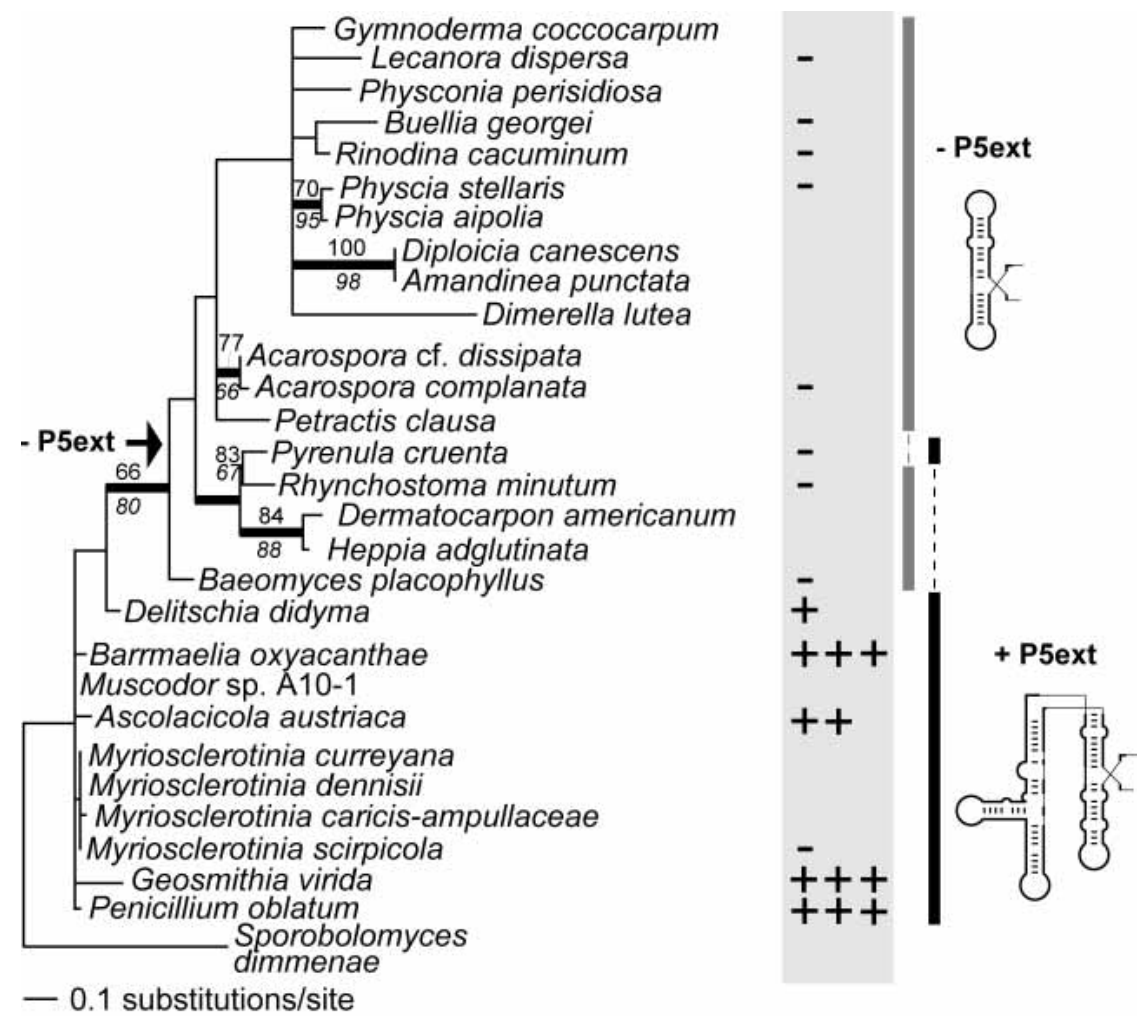

FIGURE 5. The phylogeny of S788 group I introns. This is an ML phylogenetic tree inferred from the 68 positions defined as the S788 intron catalytic core (see Fig. 1 for details). Bootstrap, quartet-puzzling, and Bayesian analysis were done as described in Fig. 4B. On the right side of the tree is a summary of the in vitro splicing results, and indicate efficient $(+++)$, moderate $(++)$, low-level $(+)$, or no $(-)$ in vitro self-splicing under our conditions. Thick vertical black lines indicate introns with an extended P5 region, whereas thick vertical gray lines indicate a short P5. The "-P5ext" intron clade is indicated with an arrow.

indicate a higher rate of intron sequence divergence after the split of Delitschia.

To better understand the nature and distribution of sequence changes in the S788 introns, the ML tree inferred from the core alignment (Fig. 5) was used in a character analysis using MacClade V4.05 (Maddison and Maddison 2002). This approach allowed us to identify nucleotides that define each branch in the core intron tree. Of the 68 core positions, three were found to unambiguously separate the $-\mathrm{P} 5$ ext from the $+\mathrm{P} 5$ ext introns. These three positions were mapped onto the secondary structure of the Baeomyces group I intron (circled in Fig. 1). To illustrate this analysis, Figure 6A shows the distribution of nucleotide changes for one of the three positions (core position 27; corresponding to position 192 in Baeomyces) on the core tree. The ancestral state "G" (black branches) changes into an "A" (gray branches) after the divergence of Delitschia and later changes to a "C" (Heppia adglutinata and Dermatocarpon americanum [open branches]) or reverts back to the ancestral state "G" in Buellia. Two of the core positions that distinguish the $+\mathrm{P} 5$ ext and $-\mathrm{P} 5$ ext intron clades are known to be involved in triplet interactions that are important for bridging the $\mathrm{P} 4-\mathrm{P} 6$ folding domain to the $\mathrm{P} 3-\mathrm{P} 7$ domain
(Michel et al. 1990). These interactions stabilize the ribozyme core and are particularly important for stabilizing a specific subgroup of small group I introns (IC3; Ikawa et al. 2000a).

The stepwise changes of all 68 core positions are shown in Figure 6B, demonstrating that in addition to the three positions mentioned above, changes have occurred throughout the intron core. This result is more consistent with a scenario of lowered selection pressure across the entire core of the -P5ext S788 introns rather than with positive selection acting on a small number of sites to facilitate the coevolution of the introns and a particular splicing factor. In summary, the ancestral state of the S788 intron appears to be an intron with a highly conserved core and an extended $\mathrm{P} 5$. In contrast, the -P5ext S788 introns have accumulated many more nucleotide changes in the core region, with three of these changes unambiguously defining the split from the ancestral state. Despite these major differences in secondary structure and in vitro splicing, the S788 introns are presumably all absent from mature SSU rRNA. Large sequence insertions such as group I introns would undoubtedly be deleterious for the host organism. In support of this idea, RT-PCR analyses confirmed in vivo intron excision for six of the fungi used in this study (summarized in Table 1 ; data not shown).

\section{Can S788 intron splicing be rescued by Cyt-18 or by TP30?}

Because all S788 introns must be removed from the precursor rRNA in vivo, we wanted to test the idea that the loss of the P5abcd paired elements (and splicing activity under our in vitro conditions) could be compensated by protein factors that stabilize the ribozyme structure. In an attempt to rescue self-splicing of the S788 introns, we incubated the inactive -P5ext introns in the presence of the Cyt-18 protein (provided by A. Lambowitz) under conditions favoring Cyt-18 activity (Guo and Lambowitz 1992), our standard splicing conditions, or variations of these two (see Materials and Methods for details). Cyt-18 is known to assist splicing in several introns by mimicking the role of P5abc (for review, see Lambowitz et al. 1999). Even though the Neurospora crassa positive control intron-RNA ( $\Delta$ ORF mtLSU) was readily activated by Cyt-18, we found no evidence of splicing rescue of the $-\mathrm{P} 5$ ext S788 introns (Fig. 7). In ad- 
A

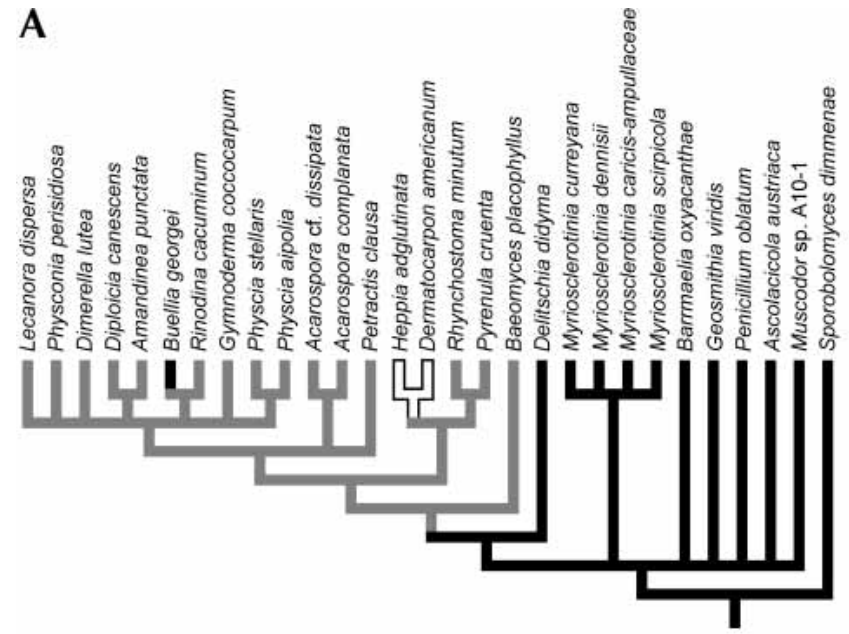

B

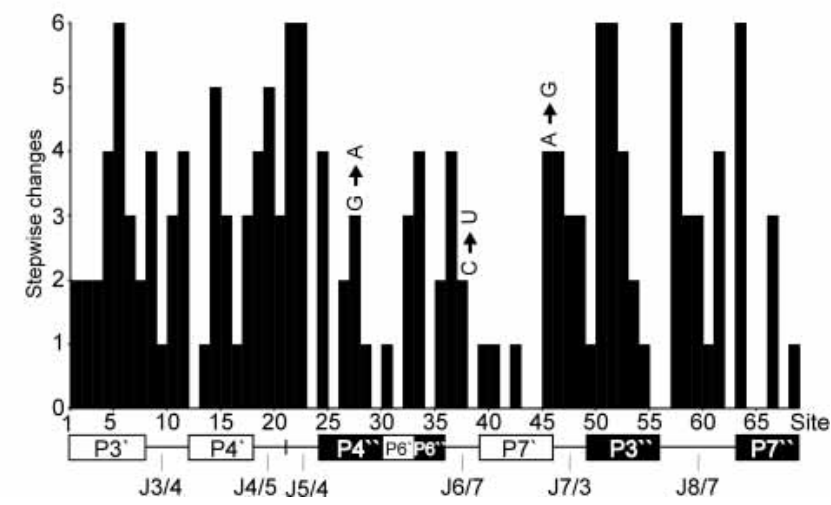

FIGURE 6. Analysis of the catalytic core region of the S788 intron. (A) Nucleotide changes at core position 27 is mapped on the intron "core" tree (i.e., the tree shown in Fig. 5). The different nucleotide states are marked as black $(\mathrm{G})$, gray $(\mathrm{A})$, or white (C). Position 27 is one of three positions $(27,37$, and 45$)$ that unambiguously separate the long from the short introns. (B) The number of stepwise nucleotide changes at each position in the catalytic core. The RNA-secondary structure position of each core site (nucleotide) is shown at bottom.

dition, RT-PCR analysis using flanking exon primers failed to amplify ligated exons with the fungal introns (data not shown).

In a similar approach, we also tried to rescue intron activity by adding a purified mixture of ribosomal proteins isolated from Escherichia coli (TP30; provided by G. Culver). We considered TP30 to be a reasonable candidate to activate the introns, perhaps in a more nonspecific fashion than Cyt-18, because ribosomal proteins are colocalized with nuclear group I introns, and they normally bind and stabilize large, structured RNAs. The S788 intron preRNAs were incubated in the presence of TP30 under various conditions, including conditions favorable for reconstitution of the 30 S ribosomal particle (Culver and Noller 1999) and our standard splicing conditions. Again PAGE gels and RTPCR analyses failed to provide evidence of intron activation. These experiments, although not exhaustive, suggest that we have either not found the correct conditions for Cyt-18and TP30-mediated splicing rescue, or perhaps more likely, that fungal-specific factors are required to activate autocatalysis in the -P5ext S788 introns. Other potential factors that might have influenced our Cyt-18 splicing results are the existence of kinetic traps in the folding of the RNAs, the absence of a RNA chaperone (like stpA; e.g. Mayer et al. 2002), or the lack of coupling between intron excision and translation.

\section{Parallel evolution of fungal rDNA group I and spliceosomal introns?}

Previously, we and others have reported the existence of many putative spliceosomal introns in the nuclear rDNA of lichen fungi (Bhattacharya et al. 2000, 2003; Cubero et al. 2000). These introns are widespread in rDNA, but found exclusively among euascomycetes, thus supporting a relatively recent origin in this group (Bhattacharya et al. 2000). The source of these invading introns remains unclear. Although they could have been transferred (e.g., through reverse-splicing; for review, see Logsdon et al. 1998) from existing introns in euascomycete pre-mRNA genes, the intriguing possibility remains that they are degraded, previously mobile group I introns. Supporting the second sce-

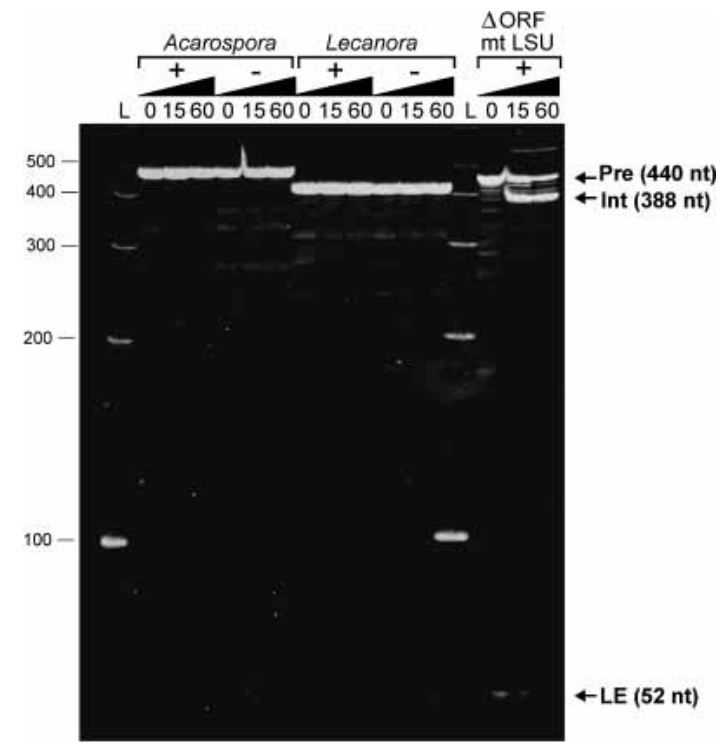

FIGURE 7. Incubation of fungal S788 introns in the presence of Cyt-18. Intron RNAs were subjected to self-splicing conditions in the presence of Cyt-18 (provided by A. Lambowitz) in time-course experiments and run on polyacrylamide gels. The results of an experiment using buffer conditions favoring Cyt-18 activity (Guo and Lambowitz 1992) are shown. A representative gel including the $\triangle \mathrm{ORF}$ mtLSU positive control intron RNA (Myers et al. 2002) and two S788 intron RNAs (Acarospora and Lecanora) incubated in the presence $(+)$ or absence (-) of Cyt-18 are presented. For the $\triangle$ ORF mtLSU intron precursor RNAs (Pre), ligated exons RNAs (LE), and excised intron RNAs (Int) are readily seen. Cyt-18 assisted self-splicing was not observed for the tested S788 introns. 
nario is the finding in maize of a spliceosomal intron that originated from a transposable element (Giroux et al. 1994). It has also been hypothesized that autocatalytic group II introns may have been the original source of spliceosomal introns in eukaryotes (e.g., Cavalier-Smith 1991; Cousineau et al. 2000; Eickbush 2000; Dickson et al. 2001). However, no data have provided direct evidence for an evolutionary link between particular autocatalytic and spliceosomal introns.

We speculate that the observed reduction in intron size, elevation in the mutation rate, and the apparent evolution of protein dependency seen in the S788 intron could culminate, in some cases, into the complete loss of group I intron RNA activity and spliceosome-mediated excision. This process would initially be gradual with the stepwise degeneration of the group I intron coincident with the evolution of protein-dependent splicing. This scenario fits well our S788 data; however, conclusive evidence is still lacking and would come from the finding of a remnant rDNA group I intron that lacks splicing-critical regions but is still recognizable as a ribozyme. A potential explanation for why we have not yet found such candidates, in spite of extensive sampling (e.g., Bhattacharya et al. 2003), is that group I intron structural hallmarks would likely disappear rapidly through genetic drift, like that proposed for protein-mediated excision of spliceosomal introns.

\section{MATERIALS AND METHODS}

\section{PCR, plasmid construction, and DNA sequencing}

Group I introns inserted at position S788 were PCR amplified and cloned into a pGEM-T vector (Promega). To obtain template DNA for PCR reactions, DNA was isolated from Lecanora dispersa (ATCC \#18293), Geosmithia virida (ATCC \#56972), Penicillium oblatum (ATCC \#56978), and Myriosclerotinia scirpicola (gift from T. Schumacher) using the Puregene DNA Isolation Kit (GENTRA Systems) following the manufacturer's protocol for filamentous fungi. Total genomic DNA extracts from Rinodina cacuminum and Buellia georgei (gift from G. Helms), Acarospora complanata, Pyrenula cruenta, and Baeomyces placophyllus (gift from F. Lutzoni), Ascolacicola austriaca, Barrmaelia oxyacanthae, Rhynchostoma minutum, and Delitschia didyma (gift from K. Winka), and Physcia stellaris (gift from D. Simon) were used directly as templates in PCR reactions. DNA templates were added to standard PCR reactions using primers PR 58 (5'-AACGAAAGTTAGGGGATCGA A-3') and PR 59 (5'-TTTAAGTTTCAGCCTTGCGA-3') to amplify the S788 intron along with a 27-bp region of the $5^{\prime}$ exon and a 140-bp region of the $3^{\prime}$ exon. Amplified PCR products of expected size were isolated from $1 \%$ agarose gels using the QIAquick gel extraction kit (QIAGEN) and ligated into pGEM-T vectors using the pGEM-T vector system (Promega). Plasmid constructs were confirmed by DNA sequencing using the ABI PRISM 3100 Genetic Analyzer (Applied Biosystems) and the Big Dye terminator chemistry (Applied Biosystems) following the manufacturer's instruction, and named according to the new proposed nomenclature of group I introns in ribosomal DNA (Johansen and Hau- gen 2001; see Table 1). Intron sequences that were found to contain sequence differences from the GenBank equivalent data have been given new GenBank accession numbers (see Table 1).

\section{In vitro transcription and splicing}

Using a modified version of a previously described protocol (Milligan and Uhlenbeck 1989), RNA was transcribed from linearized plasmids containing the intron and some (167 nt) flanking exon sequence. Restriction enzymes used to linearize the plasmids are listed in Table 1. Reactions contained $2 \mathrm{mM}$ rNTPs (each), $7 \mathrm{mM}$ $\mathrm{MgCl}_{2}, 40 \mathrm{mM}$ Tris- $\mathrm{HCl}$ ( $\mathrm{pH} 7.9$ ), $3 \mathrm{mM}$ spermidine, $0.01 \%$ Triton X-100, and $5 \mathrm{mM}$ dithiothreitol, $5 \mathrm{U}$ of T7 RNA polymerase (Stratagene) and $\sim 1 \mu \mathrm{g}$ of linearized plasmid in a total volume of $20 \mu \mathrm{L}$. Transcriptions were left at $37^{\circ} \mathrm{C}$ for $90 \mathrm{~min}$. In $15-30-\mu \mathrm{L}$ reactions, RNA transcripts were subjected to our standard selfsplicing conditions by incubation at $50^{\circ} \mathrm{C}$ over a time course of 0-60 min under the conditions described by Johansen and Vogt (1994) [40 mM Tris- $\mathrm{HCl}$ (pH 7.5), 25 mM MgCl, $1 \mathrm{M} \mathrm{KCl,} 2 \mathrm{mM}$ spermidine, $5 \mathrm{mM}$ dithiothreitol, and $0.2 \mathrm{mM} \mathrm{GTP]}$. RNA was run on a $5 \%$ polyacrylamide/8 $\mathrm{M}$ urea gel and stained with $\mathrm{EtBr}$ for visualization with a UV lamp. Intron RNAs that were spliced in the presence of Cyt-18 (gift from A. Lambowitz) were subjected to our standard conditions as described above, in $24-\mu \mathrm{L}$ reactions as previously described by Guo and Lambowitz (1992) [100 mM KCl, 5 $\mathrm{mM} \mathrm{MgCl}$, $20 \mathrm{mM}$ Tris- $\mathrm{HCl}$ ( $\mathrm{pH}$ 7.5), $5 \mathrm{mM}$ dithiothreitol, and $0.2 \mathrm{mM}$ GTP for $60 \mathrm{~min}$ at $37^{\circ} \mathrm{C}$ ], or subjected to intermediates of these two conditions (see below). First, $42^{\circ} \mathrm{C}$ was identified as an intermediate temperature that allowed both the $\triangle \mathrm{ORF} \mathrm{mtLSU}$ and the $\mathrm{S} 788$ introns to splice in their respective buffers. At $42^{\circ} \mathrm{C}$, intermediate splicing buffers were tested by eliminating spermidine from the standard high-salt buffer (i.e., there is no spermidine in the Cyt-18 buffer), and increasing the magnesium concentration from $5 \mathrm{mM}$ to $15 \mathrm{mM}$ in the Cyt-18 buffer. Intron RNAs spliced in the presence of TP30 (gift from G. Culver) were subjected to conditions as described by Culver and Noller (1999) [330 $\mathrm{mM} \mathrm{KCl}, 80 \mathrm{mM}$ Hepes (pH 7.6), $20 \mathrm{mM} \mathrm{MgCl}_{2}$ ] with $0.2 \mathrm{mM}$ GTP added in $10-20-\mu \mathrm{L}$ reactions, and incubated at $42^{\circ} \mathrm{C}$ for 60 min. Alternatively, the standard conditions were used. An approximate 1:1 molar ratio of intron RNA:TP30 was used under both conditions ( $\sim 8$ pmole each). After incubation, the RNA was extracted once with phenol:chloroform and run on a 5\% PAGE gel or used as template in RT-PCR reactions (see below).

\section{Detection of ligated exons and intron circle formation by RT-PCR}

RT-PCR was used to detect intron splicing by targeting RNAs corresponding to ligation products of the exons flanking the S788 intron. Template RNAs were total RNA extracts isolated from fungal tissue samples using the RNAeasy kit (QIAGEN), or the products of in vitro splicing reactions as described above. Firststrand synthesis was done using Superscript II reverse transcriptase (Invitrogen) and primer PR 59 in a standard reaction as recommended by the manufacturer. Three microliters of the $20 \mu \mathrm{L}$ RT reaction was subsequently used as template in a standard PCR reaction with primers PR 58 and PR 59. Products were run on 2\% $1 \times$ TBE agarose gels. Amplified DNA, consistent in size with ligated exons, was purified from the gel and DNA sequenced. To 
approximate the lower level for detection of splicing in the RTPCR approach, we did serial dilutions (up to $10^{-7}$ ) of the Barrmaelia (splicer) and Lecanora (non-splicer) splicing reactions (60 min). RT-PCR analyses of these templates (as described above) showed that we could detect ligated exons up to the $10^{-4}$ dilution of the Barrmaelia product, whereas ligated exons were not detected using any of the Lecanora dilutions (data not shown). This suggests that our RT-PCR approach was reasonably sensitive for detecting intron splicing. In a similar approach, intron RNA circle junctions were also determined by using RT-PCR. Primers used for first-strand synthesis were PR 74 (5'-CCCCCACCGACATCTA GT-3'; Penicillium oblatum), PR 70 (5'-GGAGATCCCCGCAATT T-3'; Barrmaelia oxyacanthae), PR 76 (5'-GGGCGAACCCAGCG TAGG-3'; Ascolacicola austriaca), PR 73 (5'-CATCCTGAACGTT GTTA-3'; Geosmithia virida) and PR 77 (5'-GGCTGCGGATTTC CTGTA-3'; Delitschia didyma), and the primers added to the PCR reactions were PR 69 (5'-CCCCTAAGATATAGTCGA-3'), PR 71 (5'-CCCTGTAGTGGATGCAGT-3'), PR 75 (5'-TGCAGYTCAC AGACTAAA-3'), PR 72 (5'-CCTGCAACCAAGCGCTA-3') and PR 75, respectively.

\section{Phylogenetic analyses}

To test the monophyly of the S788 introns, we compiled a data set containing 21 S788 introns (closely related taxa were excluded to minimize the data set; i.e., Physcia aipolia, Acarospora cf. dissipata, Geosmithia virida, and three of the four Myriosclerotinia species) plus an additional 26 group I introns inserted into six other SSU rDNA sites (S516, S943, S1199, S1210, S1506, and S1516). The 26 introns were sampled from ascomycete fungi and the insertion sites were chosen because they represent the most frequently occupied positions in SSU rDNA. The final data set contained $115 \mathrm{nt}$ from the catalytic core region and the phylogeny was inferred using the NJ method with a distance matrix calculated with the Jukes-Cantor (JC) evolutionary model (distances could not be calculated for these divergent data when using more complex models, e.g., LogDet, Tamura-Nei) and the MEGA 2.1 software (Kumar et al. 2001). We used Bayesian analysis (MrBayes V3.0b4, Huelsenbeck and Ronquist 2001) to calculate posterior probabilities of the nodes resolved in the intron NJ tree. Metropoliscoupled Markov chain Monte Carlo from a random starting tree was initiated in the Bayesian inference and run for 2 million generations. Trees were sampled each 100 cycles. Four chains were run simultaneously, of which three were heated and one was cold, with the initial 1,000,000 cycles (10,000 trees) being discarded as the "burn-in". Stationarity of the log likelihoods was monitored in each analysis to verify convergence by $1,000,000$ cycles (results not shown). A consensus tree was made with the remaining 10,000 phylogenies to determine the posterior probabilities at the different nodes. We also used four different bootstrap analyses to calculate support values for the intron tree. These were NJ-JC, NJKimura 2 (2000 replicates each), unweighted maximum parsimony (200 replicates), and minimum evolution-JC (2000 replicates). All analyses but the NJ-Kimura 2 (done with PAUP* V4.0b10, Swofford 2002) were done using MEGA. The intron alignment is available upon request from D.B.

Two different data sets were prepared for the detailed S788 group I intron phylogenetic analyses of taxa in the + P5ext and -P5ext groups. The first contained all unambiguously aligned positions in the data set (249 nt), whereas the second included only the sites in the ribozyme core (68 nt; see Fig. 1). Both alignments are available upon request from D.B. Intron trees were inferred from the 249- and 68-nt data sets using the ML method implemented in PAUP*. Hierarchical likelihood ratio tests were done to identify the best-fit evolutionary model for the intron data sets (MODELTEST V3.06; Posada and Crandall 1998). This analysis showed the general time reversible model (Rodríguez et al. 1990) with the $\gamma$ correction to accommodate rate variations across sites $($ GTR $+\Gamma)$ as fitting best both intron data sets. The GTR $+\Gamma$ model was, therefore, used in the ML analyses. Starting trees were built stepwise (10 random additions) and optimized with the tree bisection reconnection branch-swapping algorithm.

The stability of nodes in the intron ML trees was tested with bootstrap analysis (2000 replications) using the NJ method and distance matrices calculated with the GTR $+\Gamma$ model (using PAUP $^{*}$ ). We also used Bayesian analysis as described above. The GTR $+\Gamma$ model was used in the analysis of the 68 -nt data set, whereas we used the GTR model with site-specific $\gamma$ parameters for the core ( $68 \mathrm{nt}$ ) and the remaining positions in the 249-nt data set. And finally, we implemented quartet-puzzling maximum likelihood analysis of the 249- and 68-nt data sets with TREEPUZZLE V5.0 (Schmidt et al. 2002) using the Tamura-Nei (Tamura and Nei 1993) $+\Gamma$ model (10,000 puzzling steps) to infer support for nodes in the ML trees.

\section{ACKNOWLEDGMENTS}

This work was supported by grants DEB 01-0774 and MCB 0110252 awarded to D.B. from the National Science Foundation, a grant from The Norwegian Research Council to P.H., and an Avis E. Cone research fellowship to H.J.R. We are grateful to Dawn Simon, Gert Helms, François Lutzoni, Trond Schumacher, and Katarina Winka for providing fungal tissue and DNA, Jennifer Maki and Gloria Culver for providing purified TP30, and Sabine Mohr and Alan M. Lambowitz for providing purified Cyt-18. We would also like to thank Valérie Reeb and François Lutzoni for their help with fungal systematics and John Logsdon for a critical reading of the manuscript.

The publication costs of this article were defrayed in part by payment of page charges. This article must therefore be hereby marked "advertisement" in accordance with 18 USC section 1734 solely to indicate this fact.

Received October 8, 2003; accepted March 31, 2004.

\section{REFERENCES}

Bhattacharya, D. 1998. The origin and evolution of protist group I introns. Protist 149: 113-122.

Bhattacharya, D., Lutzoni, F., Reeb, V., Simon, D., Nason, J., and Fernandez, F. 2000. Widespread occurrence of spliceosomal introns in the rDNA genes of ascomycetes. Mol. Biol. Evol. 17: 19711984.

Bhattacharya, D., Friedl, T., and Helms, G. 2002. Vertical evolution and intragenic spread of lichen-fungal group I introns. J. Mol. Evol. 55: 74-84.

Bhattacharya, D., Simon, D., Huang, J., Cannone, J.J., and Gutell, RR. 2003. The exon context and distribution of Euascomycetes rRNA spliceosomal introns. BMC Evol. Biol. 3: 7.

Cannone, J.J., Subramanian, S., Schnare, M.N., Collett, J.R., D’Souza, 
L.M., Du, Y., Feng, B., Lin, N., Madabusi, L.V., Muller, K.M., et al. 2002. The comparative RNA web (CRW) site: An online database of comparative sequence and structure information for ribosomal, intron, and other RNAs. BMC Bioinformatics 3: 15.

Cate, J.H., Gooding, A.R., Podell, E., Zhou, K., Golden, B.L., Kundrot, C.E., Cech, T.R., and Doudna, J.A. 1996. Crystal structure of a group I ribozyme domain: Principles of RNA packing. Science 273: 1678-1685.

Cavalier-Smith, T. 1991. Intron phylogeny: A new hypothesis. Trends Genet. 7: 145-148.

Cech, T.R. 1990. Self-splicing of group I introns. Annu. Rev. Biochem. 59: $543-568$

Cech, T.R. and Golden, B.L. 1999. Building a catalytic active site using only RNA. In The RNA world (eds. R.F. Gesteland et al.). Cold Spring Harbor Laboratory Press, Cold Spring Harbor, NY.

Costa, M. and Michel, F. 1995. Frequent use of the same tertiary motif by self-folding RNAs. EMBO J. 14: 1276-1285.

Cousineau, B., Lawrence, S., Smith, D., and Belfort, M. 2000. Retrotransposition of a bacterial group II intron. Nature 404: 10181021.

Cubero, O.F., Bridge, P.D., and Crespo, A. 2000. Terminal-sequence conservation identifies spliceosomal introns in ascomycete $18 \mathrm{~S}$ RNA genes. Mol. Biol. Evol. 17: 751-756.

Culver, G.M. and Noller, H.F. 1999. Efficient reconstitution of functional Escherichia coli $30 \mathrm{~S}$ ribosomal subunits from a complete set of recombinant small subunit ribosomal proteins. RNA 5: 832843.

DePriest, P.T. and Been, M.D. 1992. Numerous group I introns with variable distributions in the ribosomal DNA of a lichen fungus. $J$. Mol. Biol. 228: 315-321.

Dickson, L., Huang, H.R., Liu, L., Matsuura, M., Lambowitz, A.M., and Perlman, P.S. 2001. Retrotransposition of a yeast group II intron occurs by reverse splicing directly into ectopic DNA sites. Proc. Natl. Acad. Sci. 98: 13207-13212.

Eickbush, T.H. 2000. Introns gain ground. Nature 404: 940-941, 943.

Flor, P.J., Flanegan, J.B., and Cech, T.R. 1989. A conserved base pair within helix $\mathrm{P} 4$ of the Tetrahymena ribozyme helps to form the tertiary structure required for self-splicing. EMBO J. 8: 3391-3399.

Giroux, M.J., Clancy, M., Baier, J., Ingham, L., McCarty, D., and Hannah, L.C. 1994. De novo synthesis of an intron by the maize transposable element Dissociation. Proc. Natl. Acad. Sci. 91: $12150-12154$

Golden, B.L. and Cech, T.R. 1996. Conformational switches involved in orchestrating the successive steps of group I RNA splicing. Biochemistry 35: 3754-3763.

Guo, Q. and Lambowitz, A.M. 1992. A tyrosyl-tRNA synthetase binds specifically to the group I intron catalytic core. Genes \& Dev. 6: 1357-1372.

Haugen, P. and Bhattacharya, D. 2004. The spread of LAGLIDADG homing endonuclease genes in rDNA. Nucleic Acids Res. 32: 20492057.

Haugen, P., De Jonckheere, J.F., and Johansen, S. 2002. Characterization of the self-splicing products of two complex Naegleria LSU rDNA group I introns containing homing endonuclease genes. Eur. J. Biochem. 269: 1641-1649.

Haugen, P., Coucheron, D.H., Rønning, S.B., Haugli, K., and Johansen, S. 2003. The molecular evolution and structural organization of self-splicing group I introns at position 516 in nuclear SSU rDNA of Myxomycetes. J. Eukaryot. Microbiol. 50: 283-292.

Haugen, P., Reeb, V., Lutzoni, F., and Bhattacharya, D. 2004. The evolution of homing endonuclease genes and group I introns in nuclear rDNA. Mol. Biol. Evol. 21: 129-140.

Hibbett, D.S. 1996. Phylogenetic evidence for horizontal transmission of group I introns in the nuclear ribosomal DNA of mushroomforming fungi. Mol. Biol. Evol. 13: 903-917.

Huelsenbeck, J.P. and Ronquist, F. 2001. MRBAYES: Bayesian inference of phylogenetic trees. Bioinformatics 17: 754-755.

Ikawa, Y., Naito, D., Shiraishi, H., and Inoue, T. 2000a. Structurefunction relationships of two closely related group IC3 intron ribo- zymes from Azoarcus and Synechococcus pre-tRNA. Nucleic Acids Res. 28: 3269-3277.

Ikawa, Y., Shiraishi, H., and Inoue, T. 2000b. A small structural element, Pc-J5/5a, plays dual roles in a group IC1 intron RNA. Biochem. Biophys. Res. Commun. 274: 259-265.

Ikawa, Y., Yoshimura, T., Hara, H., Shiraishi, H., and Inoue, T. 2002. Two conserved structural components, A-rich bulge and P4 XJ6/7 base-triples, in activating the group I ribozymes. Genes Cells 7: $1205-1215$.

Inoue, T., Sullivan, F.X., and Cech, T.R. 1986. New reactions of the ribosomal RNA precursor of Tetrahymena and the mechanism of self-splicing. J. Mol. Biol. 189: 143-165.

Jaeger, L., Michel, F., and Westhof, E. 1994. Involvement of a GNRA tetraloop in long-range RNA tertiary interactions. J. Mol. Biol. 236: $1271-1276$

Johansen, S. and Haugen, P. 2001. A new nomenclature of group I introns in ribosomal DNA. RNA 7: 935-936.

Johansen, S. and Vogt, V.M. 1994. An intron in the nuclear ribosomal DNA of Didymium iridis codes for a group I ribozyme and a novel ribozyme that cooperate in self-splicing. Cell 76: 725-734.

Kumar, S., Tamura, K., Jakobsen, I.B., and Nei, M. 2001. MEGA2: Molecular evolutionary genetics analysis software. Bioinformatics 17: 1244-1245.

Lambowitz, A.M. and Perlman, P.S. 1990. Involvement of aminoacyltRNA synthetases and other proteins in group I and group II intron splicing. Trends Biochem. Sci. 15: 440-444.

Lambowitz, A.M., Caprara, M.G., Zimmerly, S., and Perlman, P.S. 1999. Group I and group II ribozymes as RNPs: Clues to the past and guides to the future. In The RNA world (eds. R.F. Gesteland et al.). Cold Spring Harbor Laboratory Press, Cold Spring Harbor, NY.

Lehnert, V., Jaeger, L., Michel, F., and Westhof, E. 1996. New looploop tertiary interactions in self-splicing introns of subgroup IC and ID: A complete 3D model of the Tetrahymena thermophila ribozyme. Chem. Biol. 3: 993-1009.

Logsdon Jr., J.M., Stoltzfus, A., and Doolittle, W.F. 1998. Molecular evolution: Recent cases of spliceosomal intron gain? Curr. Biol. 8: 560-563.

Lutzoni, F., Pagel, M., and Reeb, V. 2001. Major fungal lineages are derived from lichen symbiotic ancestors. Nature 411: 937-940.

Maddison, D.R. and Maddison, W.P. 2002. MacClade Version 4.05. Sinauer, Sunderland, MA.

Mayer, O., Waldsich, C., Grossberger, R., and Schroeder, R. 2002. Folding of the td pre-RNA with the help of the RNA chaperone StpA. Biochem. Soc. Trans. 30: 1175-1180.

Michel, F. and Westhof, E. 1990. Modelling of the three-dimensional architecture of group I catalytic introns based on comparative sequence analysis. J. Mol. Biol. 216: 585-610.

Michel, F., Ellington, A.D., Couture, S., and Szostak, J.W. 1990. Phylogenetic and genetic evidence for base-triples in the catalytic domain of group I introns. Nature 347: 578-580.

Milligan, J.F. and Uhlenbeck, O.C. 1989. Synthesis of small RNAs using T7 RNA polymerase. Methods Enzymol. 180: 51-62.

Myers, C.A., Kuhla, B., Cusack, S., and Lambowitz, A.M. 2002. tRNAlike recognition of group I introns by a tyrosyl-tRNA synthetase. Proc. Natl. Acad. Sci. 99: 2630-2635.

Nielsen, H., Fiskaa, T., Birgisdottir, A.B., Haugen, P., Einvik, C., and Johansen, S. 2003. The ability to form full-length intron RNA circles is a general property of nuclear group I introns. RNA 9: $1464-1475$.

Ortoleva-Donnelly, L., Szewczak, A.A., Gutell, R.R., and Strobel, S.A. 1998. The chemical basis of adenosine conservation throughout the Tetrahymena ribozyme. RNA 4: 498-519.

Posada, D. and Crandall, K.A. 1998. MODELTEST: Testing the model of DNA substitution. Bioinformatics 14: 817-818.

Redecker, D., Kodner, R., and Graham, L.E. 2000. Glomalean fungi from the Ordovician. Science 289: 1920-1921.

Rodriguez, R., Olivier, J.L., Marin, A., and Medina, J.R. 1990. The general stochastic model of nucleotide substitution. J. Theor. Biol. 
142: 485-501.

Schmidt, H.A., Strimmer, K., Vingron, M., and von Haeseler, A. 2002. TREE-PUZZLE: Maximum likelihood phylogenetic analysis using quartets and parallel computing. Bioinformatics 18: 502-504.

Solem, A., Chatterjee, P., and Caprara, M.G. 2002. A novel mechanism for protein-assisted group I intron splicing. RNA 8: 412-425.

Strobel, S.A., Ortoleva-Donnelly, L., Ryder, S.P., Cate, J.H., and Moncoeur, E. 1998. Complementary sets of noncanonical base pairs mediate RNA helix packing in the group I intron active site. Nat. Struct. Biol. 5: 60-66.

Suh, S.O., Jones, K.G., and Blackwell, M. 1999. A Group I intron in the nuclear small subunit rRNA gene of Cryptendoxyla hypophloia, an ascomycetous fungus: Evidence for a new major class of group I introns. J. Mol. Evol. 48: 493-500.

Swofford, D.L. 2002. PAUP*: Phylogenetic analysis using parsimony ( ${ }^{*}$ and other methods) Version 4.0b8. Sinauer, Sunderland, MA.

Tamura, K. and Nei, M. 1993. Estimation of the number of nucleotide substitutions in the control region of mitochondrial DNA in humans and chimpanzees. Mol. Biol. Evol. 10: 512-526.

Tanabe, Y., Yokota, A., and Sugiyama, J. 2002. Group I introns from Zygomycota: Evolutionary implications for the fungal IC1 intron subgroup. J. Mol. Evol. 54: 692-702.

Taylor, T.N., Hass, H., and Kerp, H. 1999. The oldest fossil ascomycetes. Nature 399: 648. 

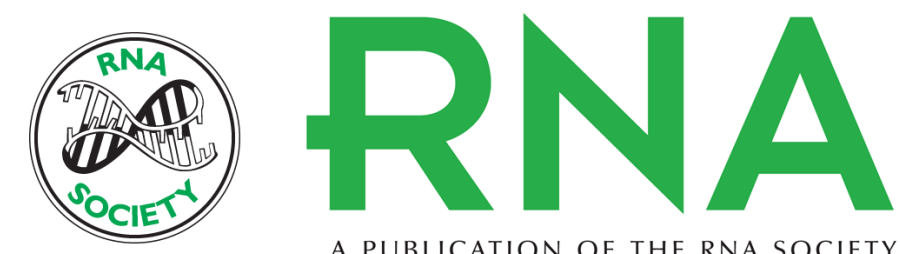

A PUBLICATION OF THE RNA SOCIETY

\section{Long-term evolution of the $\mathbf{S 7 8 8}$ fungal nuclear small subunit rRNA group I introns}

PEIK HAUGEN, HENRY JOSEPH RUNGE and DEBASHISH BHATTACHARYA

RNA 2004 10: 1084-1096

References This article cites 52 articles, 10 of which can be accessed free at: http://rnajournal.cshlp.org/content/10/7/1084.full.html\#ref-list-1

\section{License} Email Alerting
Service $\begin{aligned} & \text { Receive free email alerts when new articles cite this article - sign up in the box at the top } \\ & \text { right corner of the article or click here. }\end{aligned}$

To subscribe to RNA go to:

http://rnajournal.cshlp.org/subscriptions 